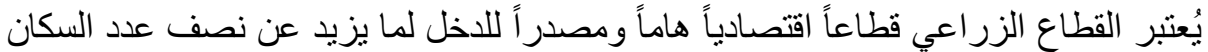

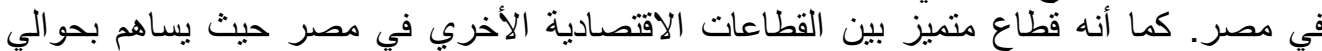

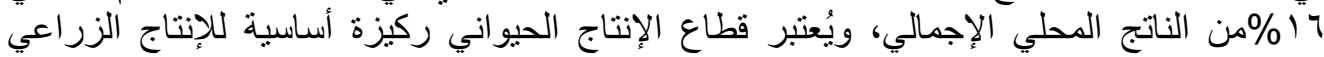

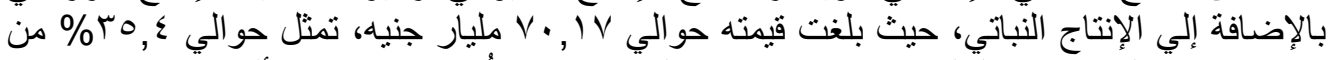

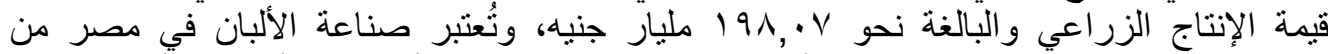

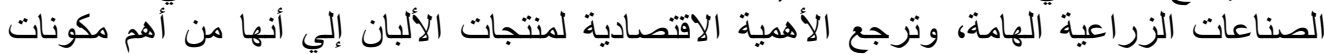

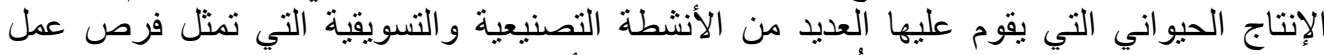

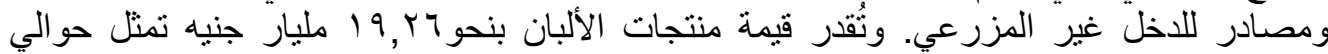

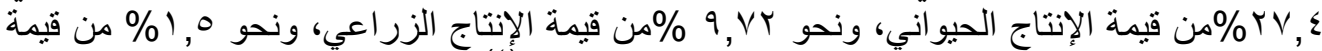

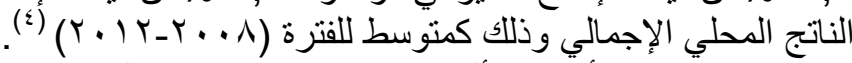

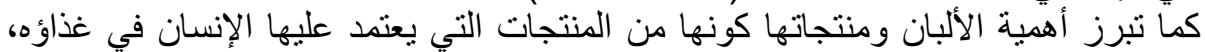

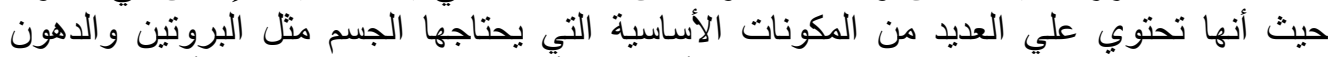

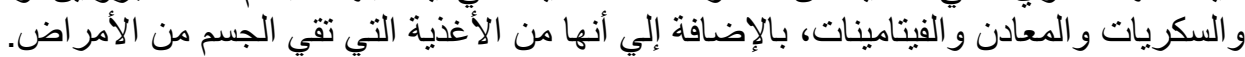

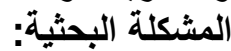

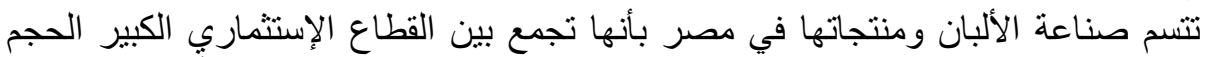

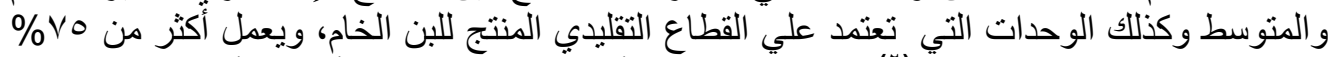

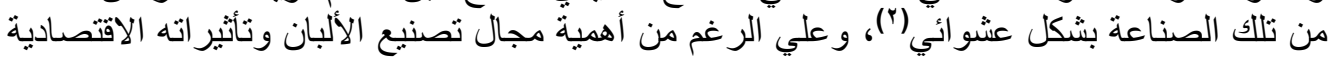

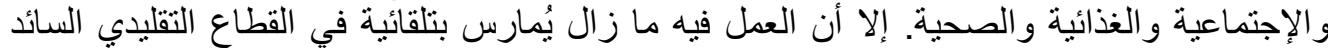

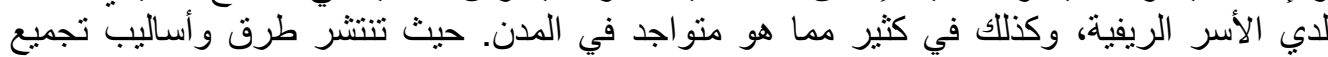

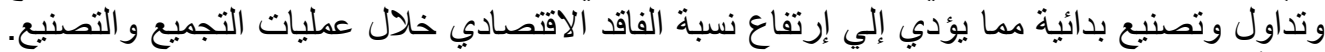

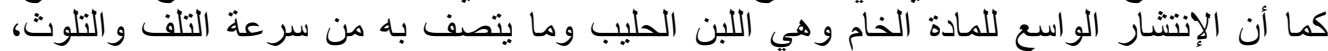

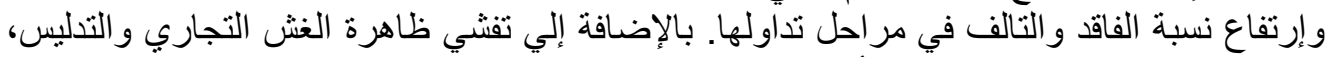

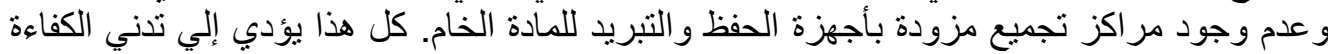

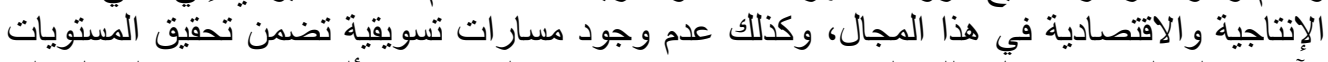

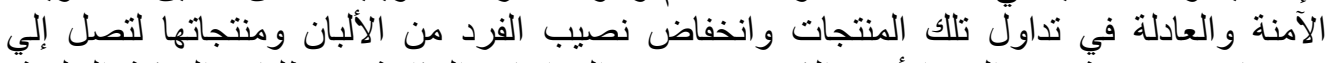

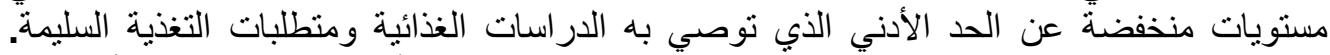

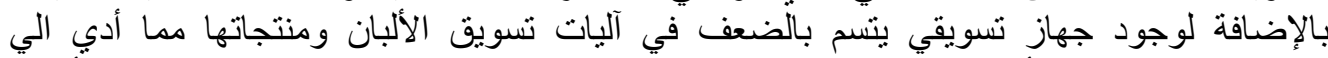

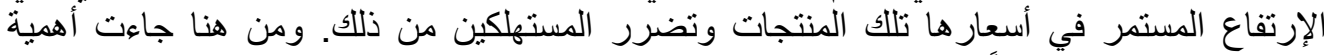
إجر اء هذه الدر اسة إستناداً لبيانات ميدانية في محافظة الفيوم.

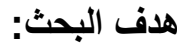
1- تقدير الكفاءة الإتتاجية والاقتصادية في كافة مر احل تصنيع وتداول الألبان ومنتجاتها في محافظة الفيوم. r- تقدير القيمة المضافة لمخرجات الإنتاج في مختلف حلقات تصنيع الألبان ومنتجاتها. 
IV

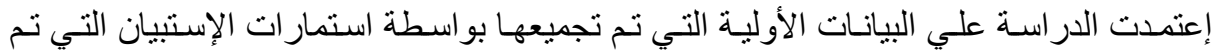

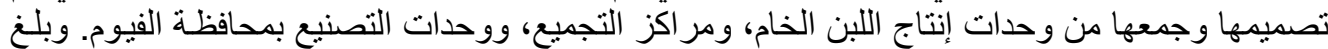

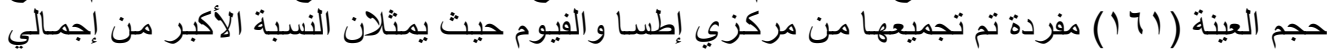

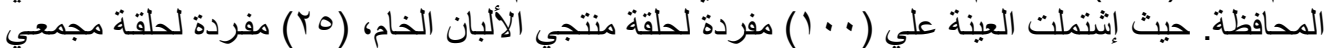

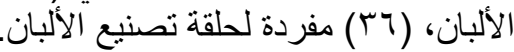

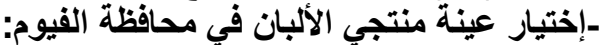

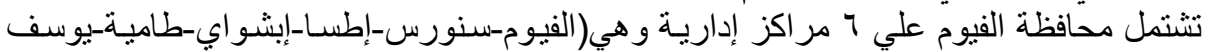

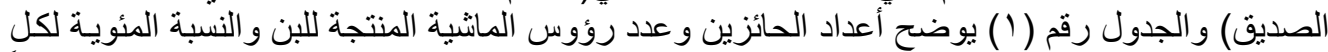

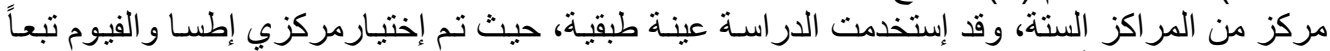

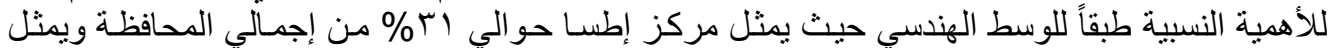

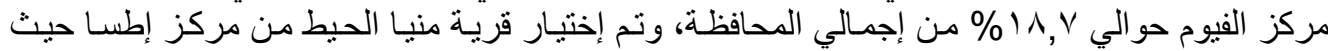

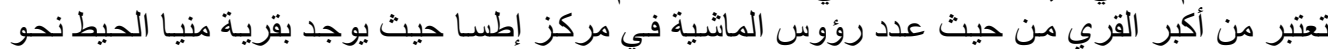

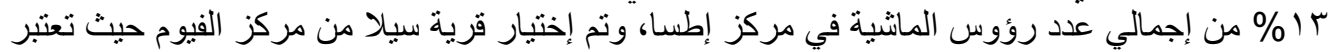

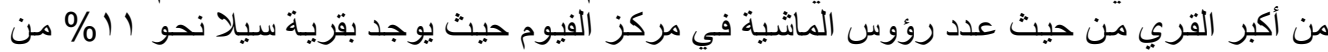

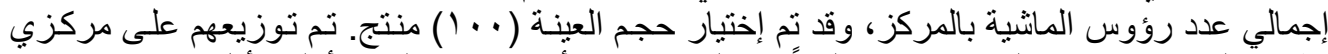

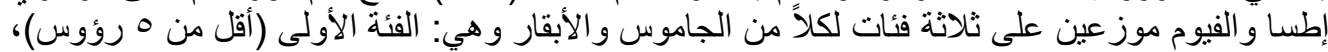

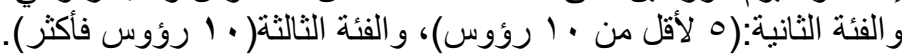
- توزيع فئات العينة علي القري المختارة:

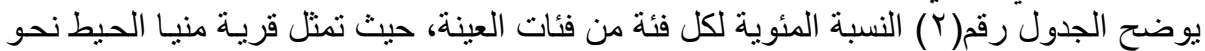

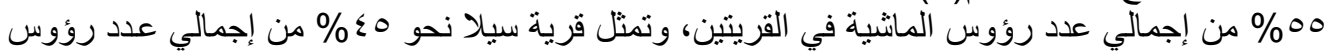

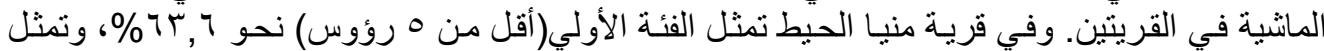

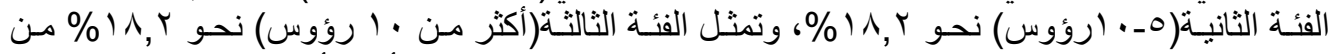

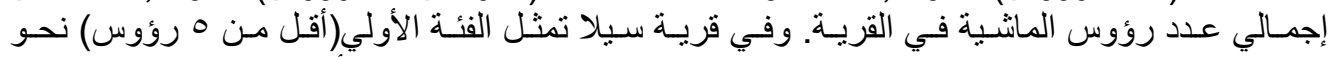

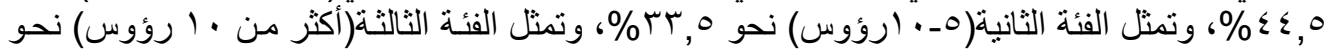

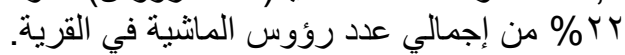

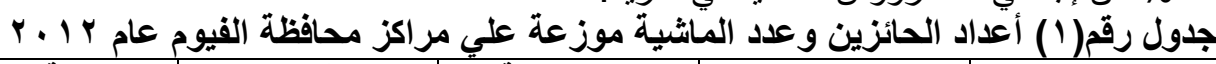

\begin{tabular}{|c|c|c|c|c|}
\hline النسبة المئوية & الوسط اللهذسي & عدد الماشية & عدد الحائزين & المركز \\
\hline r & $90 \times 0$ & Yloro & EYT. & إطسـا \\
\hline $\mid r, \wedge 1$ & $\leqslant r \circ 9$ & 710. & 190. & أبشواي \\
\hline 10 & 5719 & 97\%. & YYIA & طامية \\
\hline 11,174 & OV৯T & IYVA. & Tצr. & الفيوم \\
\hline $1 \cdot, \mathrm{V}$ & rrql & $0 \leqslant V$. & 191. & يوسف الصديق \\
\hline $1 \cdot, V K$ & III & 7190 & 109. & سنورس \\
\hline $1 \cdots$ & $r \cdot \lambda \varepsilon 1$ & $\pi Y \leq \varepsilon$. & 10711 & الإجمالي \\
\hline
\end{tabular}

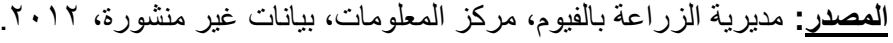

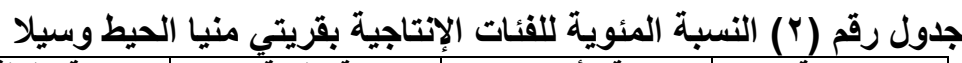

\begin{tabular}{|c|c|c|c|c|}
\hline الإجمالي & الفئة الثالثة \% \% & الفئة الثانية \% & الفئة الأولي \% & القرية \\
\hline 1.. & $1 \Lambda, r$ & $1 \Lambda, Y$ & 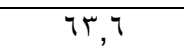 & منيا الحيط \\
\hline $1 \ldots$ & TY & $r \mu, 0$ & $\varepsilon \varepsilon, 0$ & سيلا \\
\hline
\end{tabular}

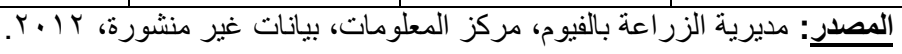

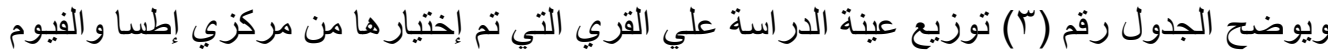

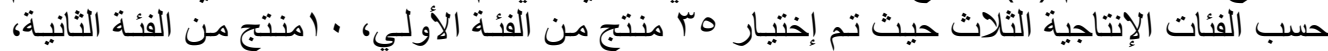

Fayoum J. Agric. Res. \& Dev., Vol. 30, No.1, January, 2016 
71

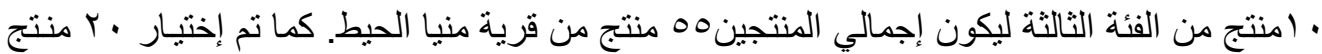

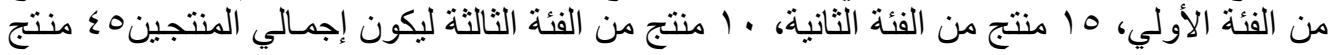

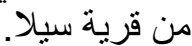

جدول رقم (ب) توزيع فئات الحيازة في العينة على القري المختارة

\begin{tabular}{|c|c|c|c|c|}
\hline المجموع & أكثر من · ا رؤوس & هـ. 1 رؤوس & اقل من • رؤوس & القرية \\
\hline 00 & 1 & 1 & ro & منبا الحبط \\
\hline$\leqslant 0$ & 1. & 10 & $r$. & سيلا \\
\hline $1 \ldots$ & r. & ro & 00 & المجموع \\
\hline
\end{tabular}

مناقثة النتائج:

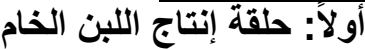
1ـالتكاليف الإنتاجية لحيو انتات إنتاج اللبن:

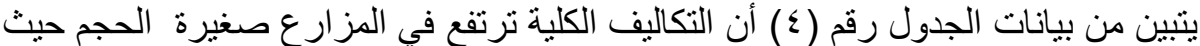

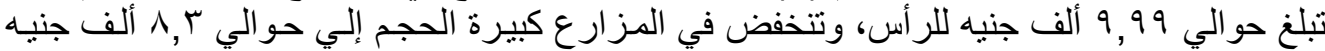

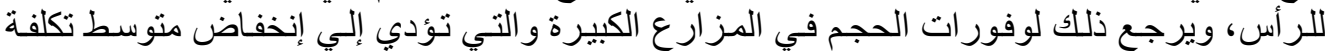

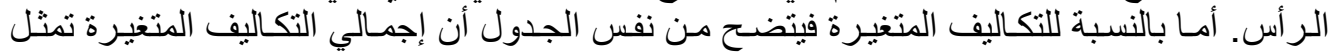

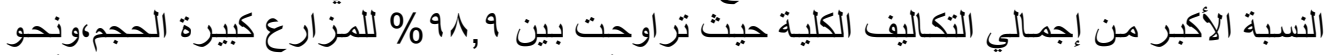

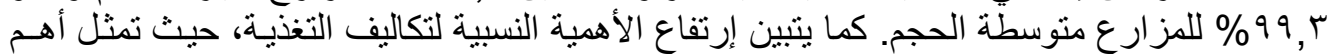

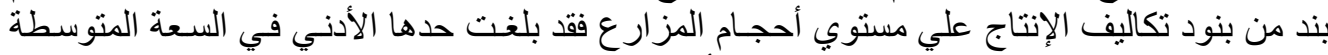

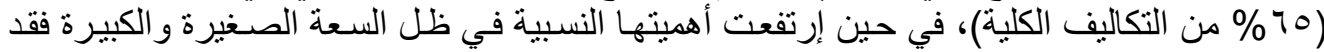

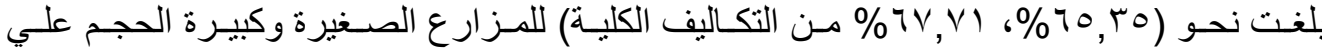

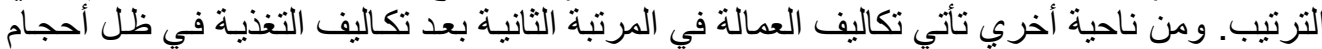

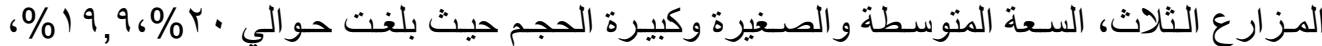

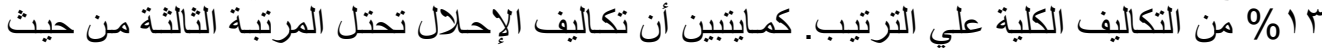

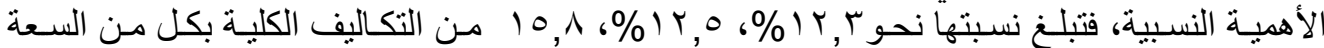

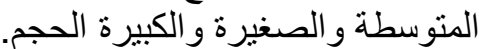
r ـ قيمة الإيراد الكلى لحيوانات الكيرة إنتاج اللبن:

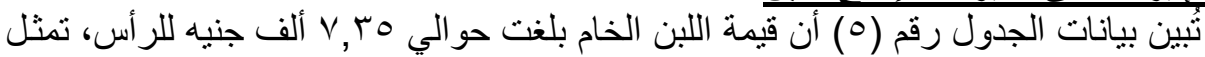

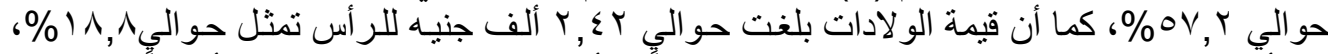

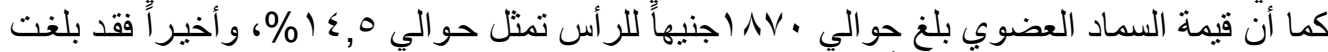

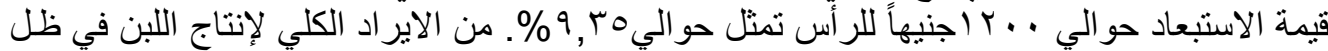

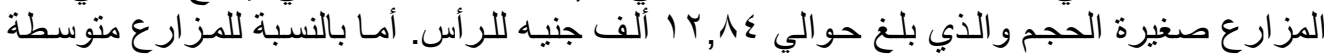

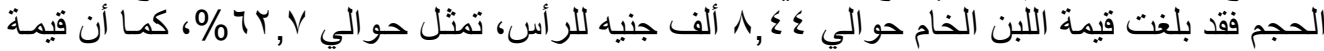

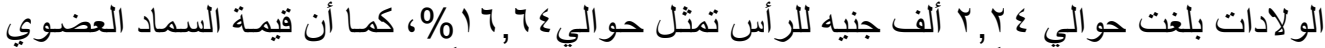

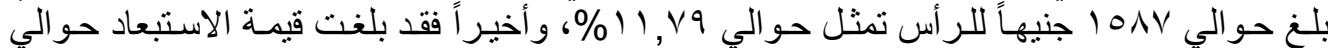

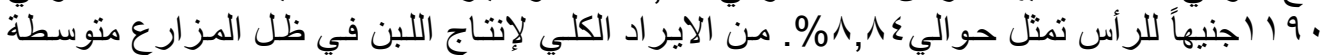

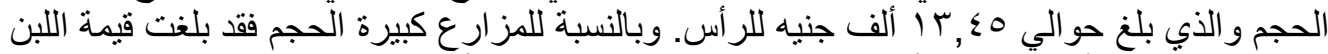

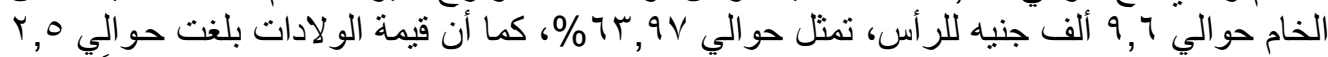

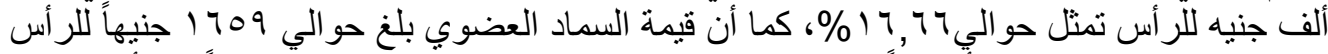

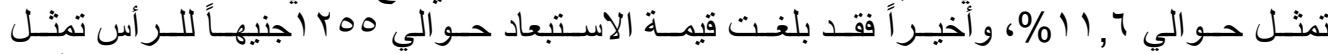

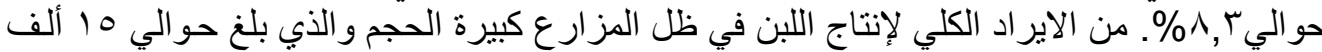

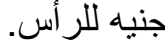

Fayoum J. Agric. Res. \& Dev., Vol. 30, No.1, January, 2016 
79

جدول رقم (ع) هيكل التكاليف الإنتاجية لحيوانات إنتاج اللبن وفقاً لسعة المزرعه بمحافظة الفيوم

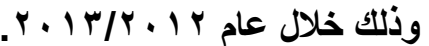

\begin{tabular}{|c|c|c|c|c|c|c|}
\hline \multicolumn{2}{|c|}{ (أكثر من · · رؤوسة الكبيرة } & \multicolumn{2}{|c|}{ (السعة المتوسطة } & \multicolumn{2}{|c|}{ (أقل من ه رؤوسفرة) } & \multirow[t]{2}{*}{ البيــان } \\
\hline$\%$ & القيمة جنيه & $\%$ & القيمة جنيه & $\%$ & القيمة جنيه & \\
\hline & & & & & & التكاليف المتغيرة \\
\hline$T V, V)$ & $07 \varepsilon$. & 70 & TrqV & 70,10 & 70\%. & التظذية \\
\hline $1 \pi$ & 1.10 & T. & 1910 & 19,94 & 1991 & عمالة عادية"'T \\
\hline 10,10 & ITY. & q & ITY. & $|r, 0|$ & ITO. & الاحلال \\
\hline 1,07 & Ir. & $1, \cdot v$ & 1.0 & $\cdot 9 V$ & $9 V$ & الألوية وأجر الطبيب \\
\hline$\cdot, \leqslant T$ & r & • & ru & $\cdot, Y_{1}$ & YI & المياة والكهرباء|") \\
\hline 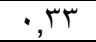 & rA & $\cdot, r$ & $r \cdot$ & $\cdot, Y_{O}$ & ro & التكاليف المتغيرة الأخرى \\
\hline \multirow{2}{*}{91,94} & Arrq & $99, r$ & $9 V V r$ & $99, Y Y$ & $991 \leqslant$ & إجمالى التكاليف المتغيرة \\
\hline & & & & & & التكاليف الثابتة \\
\hline$\cdot, \mathrm{\vee} \wedge$ & 70 &., $0 \mathrm{~V}$ & 07 & י & $\pi$ & أهلاك المبانى (") \\
\hline$\cdot, r$ & ro & $\cdot, 1 T$ & IT & $\cdot, 10$ & 10 & أهلاك الالات \\
\hline $1, \cdot 1$ & 9. & $\cdot, \mathrm{V}$ & 71 & $\cdot, \mathrm{VA}$ & $V V$ & إجمالى التكاليف الثابتة \\
\hline $1 \ldots$ & NTrq & $1 \ldots$ & $9 \wedge \Sigma 1$ & $1 \ldots$ & 9991 & التكاليف الكلية \\
\hline
\end{tabular}

التكاليف المتغيرة الأخري عبارة عن نكاليف ( التلقيح، الخسائر الرأسمالية ).

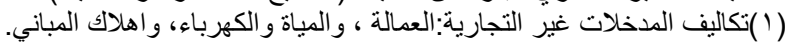

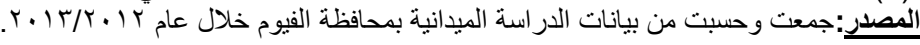

جدول رقم (•) تقديرات قيمة الإيراد الكلى لحيوانات إنتاج اللبن وفقاً لسعة المزرعة بمحافظة

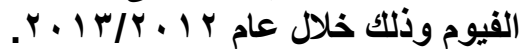

\begin{tabular}{|c|c|c|c|c|c|c|}
\hline \multicolumn{2}{|c|}{ (أكثر من · ال روئوسة) } & \multicolumn{2}{|c|}{ (السعة المتوسطة } & \multicolumn{2}{|c|}{ 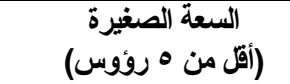 } & \multirow[t]{2}{*}{ البيـــان } \\
\hline$\%$ & القيمة جنيه & $\%$ & القيمة جنيه & $\%$ & القيمة جنيه & \\
\hline $7 r, 9 V$ & $97 \ldots$ & $T Y, V Y$ & $\wedge \varepsilon \varepsilon$ & $O V, Y \leq$ & VTO. & اللبن \\
\hline 17,77 & ro.. & $17,7 \varepsilon$ & TYE. & $1 \wedge, \wedge \varepsilon$ & $T \leq Y$. & الولادات \\
\hline 11,7 & 1709 & 11,19 & $10 \mathrm{NV}$ & $1 \leqslant, 07$ & $1 \wedge V$. & السماد \\
\hline$\Lambda, r$ & 1100 & $\wedge, \wedge \varepsilon$ & 119. & $9, r_{0}$ & IT.. & الإستبعداد \\
\hline $1 \ldots$ & 10.10 & $1 \ldots$ & $1 T \leqslant 0 V$ & $1 \ldots$ & ITAE. & الإيراد الكلى \\
\hline
\end{tabular}

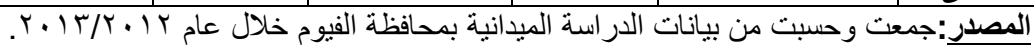

بـ - مؤشرات الكفاءة الاقتصادية:

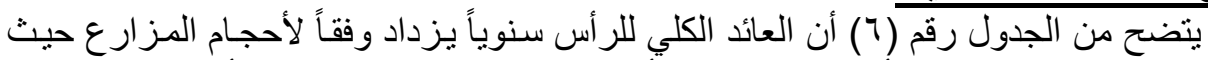

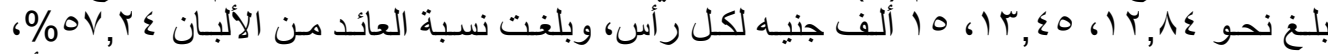

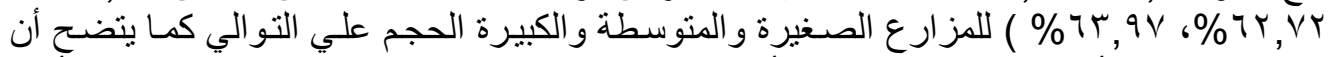

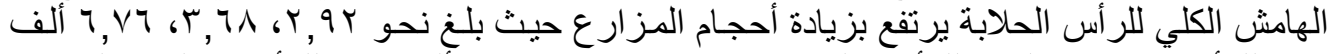

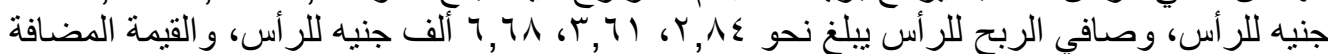

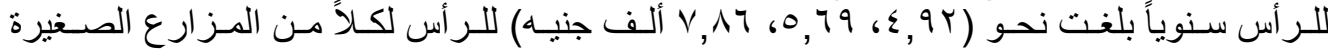

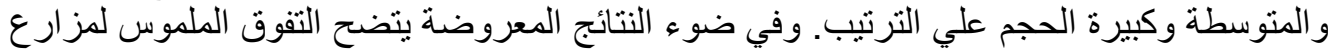
إنتاج اللبن في السعة الكبيرة علي مستوي المؤشر ات السيرة السابقة.

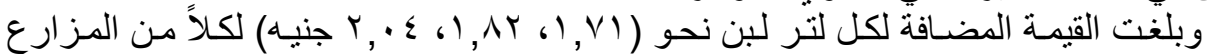

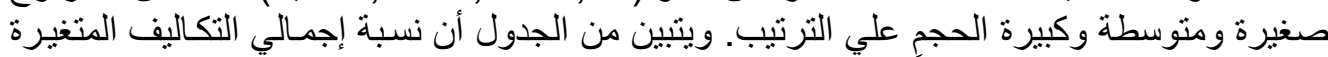

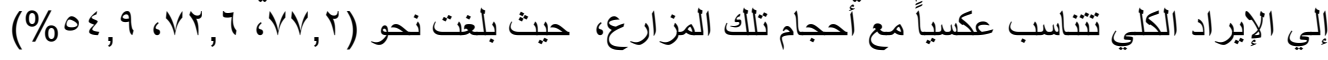

Fayoum J. Agric. Res. \& Dev., Vol. 30, No.1, January, 2016 
$\mathrm{V}$.

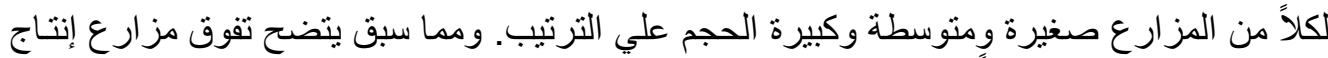

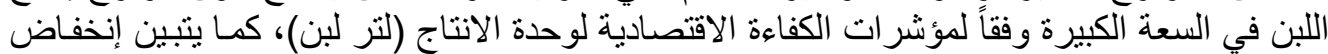

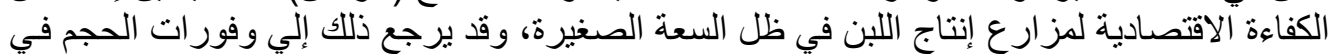

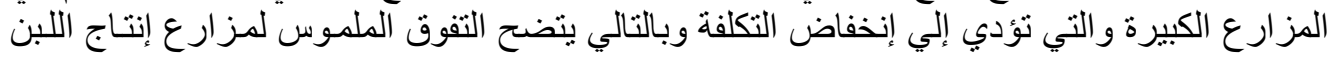

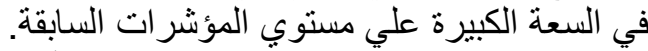

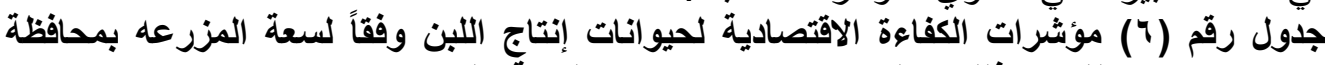

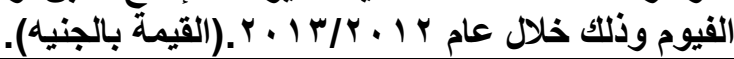

\begin{tabular}{|c|c|c|c|}
\hline (أكثر من · السعة الكبيرة رؤوس) & (السعة المتوسطة & (أقل من • روئوسة) الصغيرة) & البيـــان \\
\hline $10 \ldots 0$ & $1 r \leqslant 0 V$ & $1 Y \wedge \leq$ & العائد الكلى للرأس سنوياً \\
\hline $94,9 \vee$ & $M r, V Y$ & $\Delta V, Y \leq$ & العائد من اللبن \% \\
\hline$r q, \cdot r$ & $r v, r \Lambda$ & $\varepsilon r, \vee \uparrow$ & العائد من غير الألبان \% \\
\hline$\Lambda F 19$ & $9 \wedge \leqslant 1$ & 9991 & إجمالى التكاليف الإتتاجية للرأس سنوياً \\
\hline $9 \wedge, q 4$ & $99, r$ & $9 q, Y r$ & التكاليف المتغيرة \% \\
\hline 1,1 & $\cdot, \mathrm{V}$ & $\cdot, \vee \wedge$ & التكاليف الثابتة \% \\
\hline$v 1 \leq r$ & VVT & VqIV & تكاليف المدخلات التجارية \\
\hline 1187 & $r \cdot V V$ & $r \cdot V \leq$ & تكاليف المدخلات غير التجارية \\
\hline $7 \vee 79$ & MभL & rqrq & الهامش الكلى للرأس سنوياً \\
\hline $1,7 \leqslant$ & $1,7 r$ & $1, \leqslant 9$ & الهامش الكلى للتر اللبن \\
\hline รท人ร & พั1 & $r \wedge \leqslant q$ & صافى الربح للرأس سنوياً \\
\hline $1, \leqslant V$ & $1, r q$ & 1,17 & صافى الربح للتر اللبن \\
\hline$\cdot, \wedge$ & $\cdot, \mathrm{Mr}$ & $\cdot, r \wedge$ & الربح للجنيه المنفق \\
\hline $01, \mu r$ & $\leqslant 0,9 \leqslant$ & $\varepsilon r, Y \leqslant$ & حافز المنتج لكل لتر لبن \% \\
\hline $1, \leqslant v$ & $1, r q$ & 1,17 & هامش المنتج لكل لتر لبن \\
\hline VАฯ & 0794 & $\varepsilon q r r$ & القيمة المضافة للر أس سنوياً \\
\hline$r, \cdot \varepsilon$ & $1, \wedge r$ & $1, v_{1}$ & القيمة المضافة لكل لتر لبن \\
\hline $0 \leqslant, 9$ & $V Y, T$ & $V V, Y$ & إجمالى التكاليف المتغيرة/الإيراد الكلي \% \\
\hline
\end{tabular}

المصدر: جمعت وحسبت من الجدول (£)، (0).

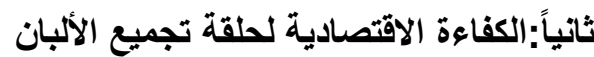

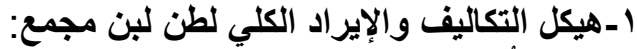

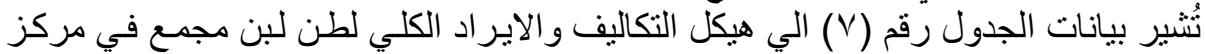

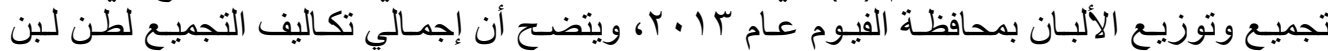

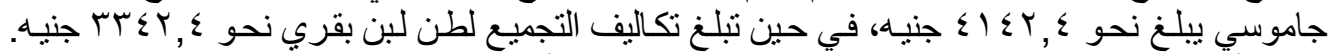

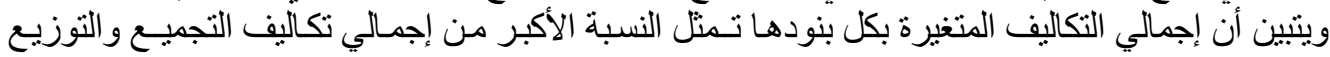

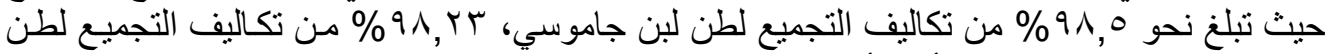

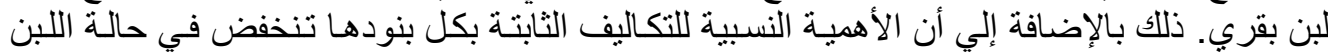
الجاموسي حيث تبلغ نحو 0, 1 \% في حين ترتفع الأهمية النسبية للتكاليف الثنابتة في حالة اللبن البقري

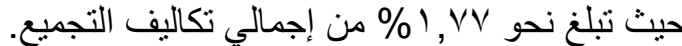

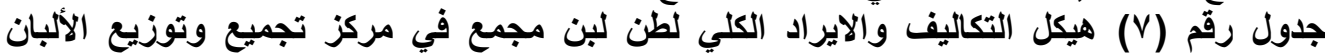

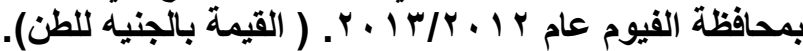

\begin{tabular}{|c|c|c|c|c|}
\hline الاهمية النسبية \% & اللبن البقري & الاهمية النسبية \% & اللبن الجاموسي & البيـان \\
\hline & $r, 0$ & & $\varepsilon, \xi$ & بيع كجم اللبن المجمع \\
\hline
\end{tabular}

Fayoum J. Agric. Res. \& Dev., Vol. 30, No.1, January, 2016 
V)

\begin{tabular}{|c|c|c|c|c|}
\hline & $1 \ldots$ & & $1 \ldots$ & كمية اللبن المجمع كجم \\
\hline \multirow[t]{4}{*}{$1 \ldots$} & ro.. & $1 \ldots$ & $\varepsilon \varepsilon \ldots$ & الإيراد الكلى \\
\hline & & & & تكاليف التجميع و التوزيع \\
\hline & & & & التكاليف المتغيرة \\
\hline & $r, r$ & & $\varepsilon$ & سعر شر اء كجم اللبن الخام \\
\hline$q 0, \vee r$ & r... & 97,0 & $\varepsilon \ldots$ & قيمة اللبن الخام \\
\hline 1,19 & $\varepsilon$ & $\cdot 97$ & $\varepsilon$ & العمالة(') \\
\hline$\cdot, 1 \leqslant$ & 0 & $\cdot, 1 r$ & 0 & المياة والكهرباء)(') \\
\hline $1, \cdot V$ & rq & $\cdot, \wedge 7$ & ry & الوقود \\
\hline$\cdot, \cdot V$ & $Y, \varepsilon$ & $\cdot, \cdot 7$ & $r, \varepsilon$ & مو اد وفحص وتحليل \\
\hline \multirow[t]{2}{*}{$q \wedge, r^{\mu}$} & rrAr, s & $9 \wedge, 0$ & $\varepsilon \cdot \wedge r, \varepsilon$ & إجمالى التكاليف المتغيرة \\
\hline & & & & التكاليف الثابتة \\
\hline$\cdot, r \leq$ & $\Lambda$ &., 19 & $\Lambda$ & الإيجار(") \\
\hline$\cdot, 1 \leqslant$ & 0 & $\cdot, 1 r$ & 0 & اهلاك عبو ات اللبن \\
\hline$\cdot, \leqslant Y$ & $1 \leqslant$ & $\cdot r \mu$ & $1 \leqslant$ & اهلاك المعدات و الالات \\
\hline$\cdot, r$ & 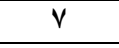 & $\cdot, 1 \mathrm{~V}$ & $\mathrm{~V}$ & الصيانة و الاصلاحات \\
\hline$\cdot, v_{0}$ & ro & $\cdot, 7$ & ro & الفائدة المقدرة علي رأس المال \\
\hline $1, V \vee$ & 09 & 1,0 & 09 & إجمالى التكاليف الثابتة \\
\hline $1 \ldots$ & $r r \leq r, \varepsilon$ & $1 \ldots$ & $\varepsilon 1 \leqslant r, \varepsilon$ & إجمالى تكاليف التجميع و التوزيع \\
\hline
\end{tabular}

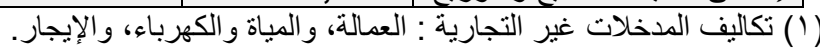

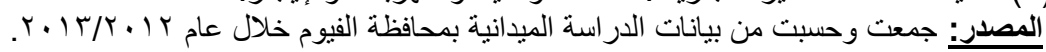

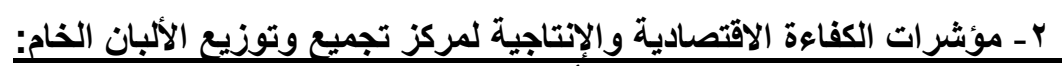

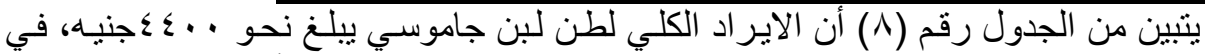

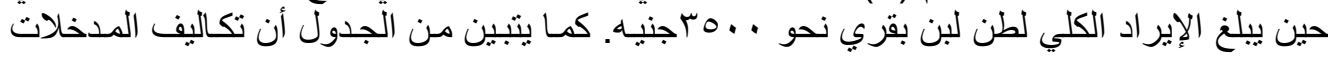

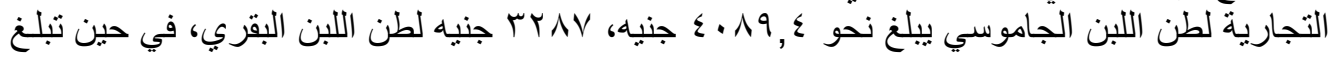

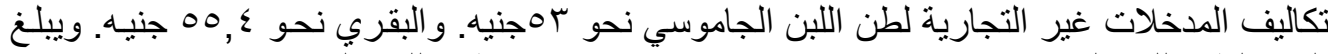

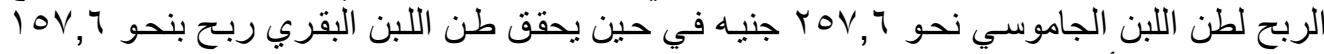

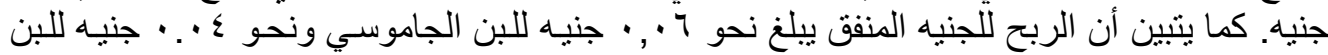

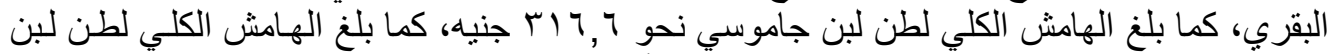

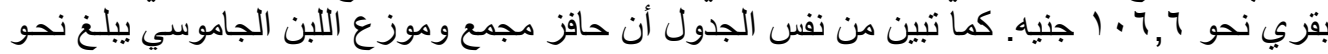

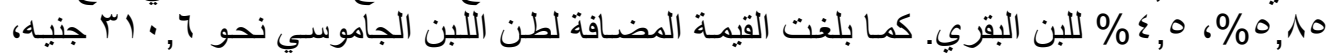

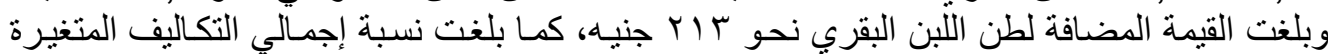

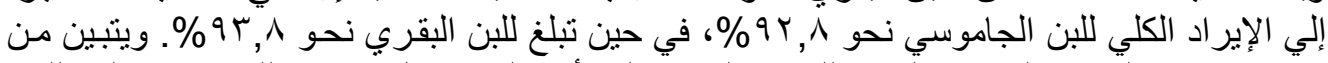

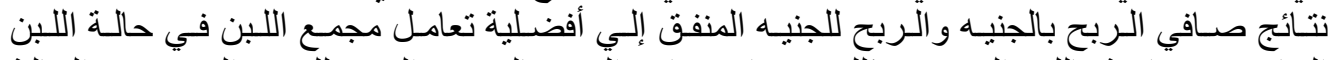

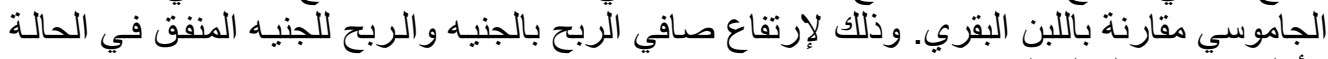
الأولي مقارنة بالحالة الثنانية. جدول رقم(^): مؤشرات الكفاءة الاقتصادية والإنتاجية لمركز تجميع وتوزيع الألبان بمحافظة الفيوم عام

\begin{tabular}{|c|c|c|}
\hline اللبن البقري & اللبن الجاموسي & البيان \\
\hline ro.. & $\varepsilon \varepsilon \ldots$ & الإبر اد الكلى لطن لبن مجمع وموزع \\
\hline 09 & 09 & التكاليف الثابتة لطن لَبن \\
\hline TYAT, \& & $\varepsilon \cdot \wedge r, \varepsilon$ & التكاليف المتغيرة لطن لبن \\
\hline$r r \leqslant r, \varepsilon$ & $\varepsilon) \leqslant r, \varepsilon$ & إجمالى تكاليف التجميع والتوزيع لطن لبن \\
\hline TYAV & $\varepsilon \cdot \wedge 9, \varepsilon$ & تكاليف المدخلات التجارية لطن لبن \\
\hline $00, \varepsilon$ & or & تكاليف الدذخلات غير التجارية لطن لبن \\
\hline
\end{tabular}

Fayoum J. Agric. Res. \& Dev., Vol. 30, No.1, January, 2016 
VY

\begin{tabular}{|c|c|c|}
\hline ITr,A & $7 \mu$ & الربح لمركز التجميع (جنيه/ يوم) \\
\hline $10 V, 7$ & rov, 7 & الربح لطن اللبن \\
\hline$\cdot, \cdot \varepsilon$ & $\cdot, \cdot 7$ & الربح للجنيه المنفق \\
\hline $10, r$ & 191,0 & الهامش الكلى لمركز التجميع (جنيه/ يوم) \\
\hline $1 \cdot 7,7$ & M17,7 & الهامش الكلى لطن لبن \\
\hline$\varepsilon, 0$ & 0,10 & حافز مجمع وموزع اللبن \% \\
\hline $10 V, 7$ & rOV, 7 & هامش المجمع لطن اللبن \\
\hline $1 V \cdot, \varepsilon$ & $V \vee 7,0$ & القيمة المضافة لمركز التجميع جنيه/ بوم \\
\hline rir & $M \cdot, 7$ & القيمة المضافة لطن اللبن \\
\hline$q \mu, \wedge$ & $9 r, \Lambda$ & إجمالى التكاليف المتغيرة/الإير اد الكلي \% \\
\hline
\end{tabular}

المصدر: جمعت وحسبت من الجدول (Y).

ثالثاً:الكفاوة الاقتصادية لحلقة تصنيع الألبان

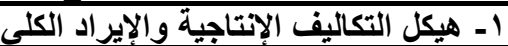

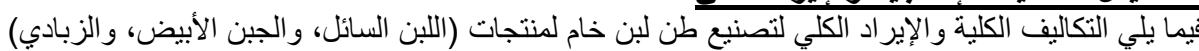
أ-تكاليف تصنيع طن لبن خام لمنتج اللبن السائل:

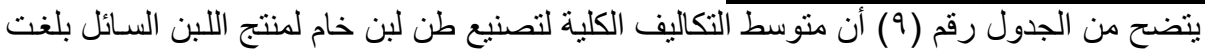

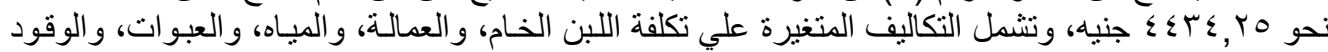

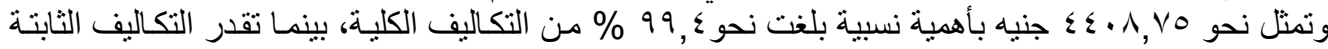

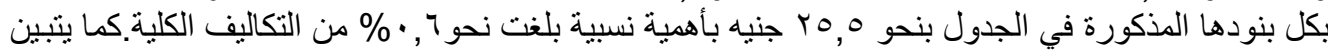

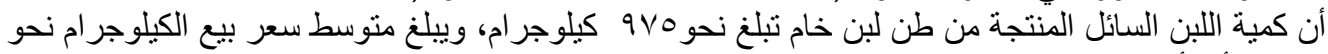

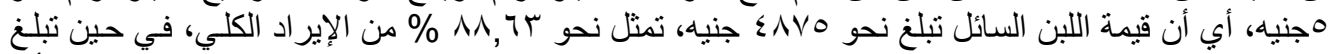

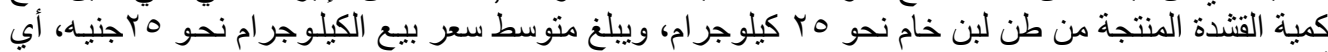

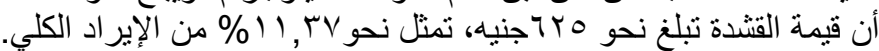
ب-تكاليف تصنيع طن لبن خام لمنتج الجبن الأبيض:

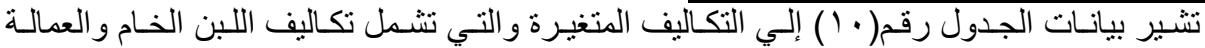

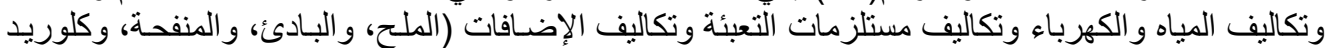

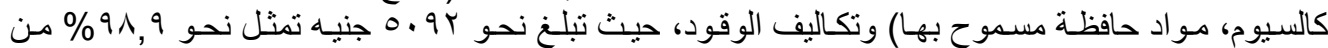

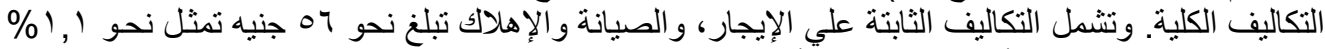

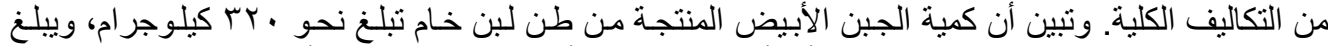

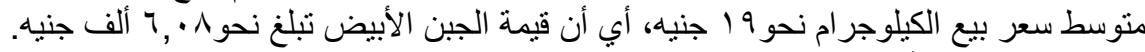
ج-تكاليف تصنيع طن لبن خام لمنتج الزبادي:

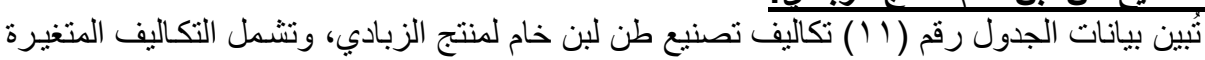

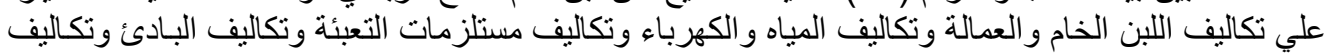

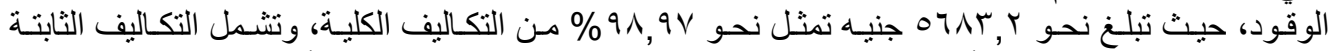

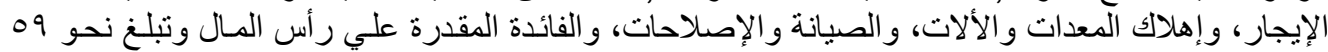

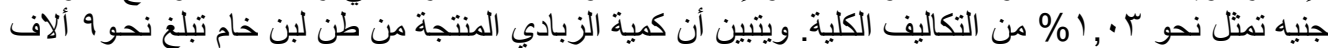

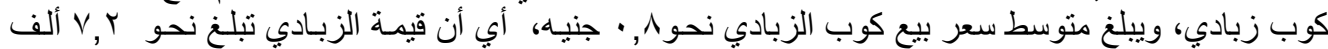

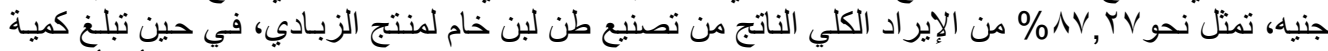

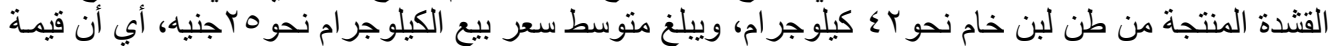

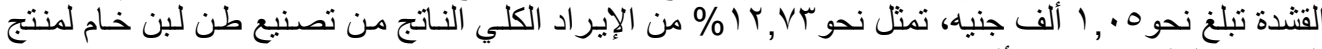

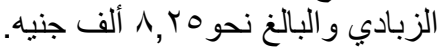

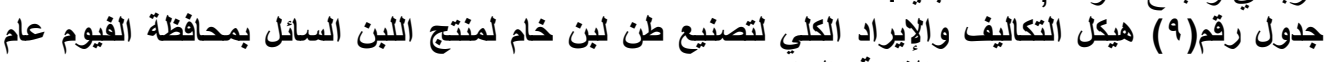

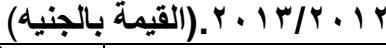

\begin{tabular}{|c|c|c|c|c|}
\hline الأهمية النسبية \% & 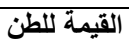 & السعر & الكمية للطن & البيان \\
\hline$\wedge \wedge, 4 \pi$ & $\varepsilon \wedge V_{0}$ & 0 & $9 \times 0$ & الكمية المنتجةٌ من اللبن السائل كجم \\
\hline $11, \Gamma v$ & 7ro & ro & ro & الكمية المنتجة من القندة كجم \\
\hline \multirow[t]{2}{*}{$1 .}$. & $00 \ldots$ & & & الإيراد الكلي \\
\hline & & & & التكاليف التنغيرة \\
\hline
\end{tabular}

Fayoum J. Agric. Res. \& Dev., Vol. 30, No.1, January, 2016 
Vr

\begin{tabular}{|c|c|c|c|c|}
\hline $90, \wedge \varepsilon$ & $\varepsilon$ ro. & $\varepsilon, Y_{0}$ & $1 \ldots$ & اللبن الخام كجم \\
\hline 1, ro & 7. & $r$ r. & $r$ & عدد العمالة (1) \\
\hline$\cdot, 10$ & 7,0 & & & المياه و الكهرباء (1) \\
\hline 1 & $\varepsilon \wedge, \vee 0$ & $\cdot, .0$ & $9 \vee 0$ & عبوات اللبن السائل \\
\hline$\cdot, 09$ & $r \uparrow, 0$ & $r, r$ & IT & عبو ات القشدة \\
\hline$\cdot, \varepsilon Y$ & 19 & & & الوقود \\
\hline \multirow[t]{2}{*}{$99, \varepsilon r$} & $\varepsilon \varepsilon \cdot \wedge, \vee 0$ & & & إجمالي التكاليف المتغيرة \\
\hline & & & & ألتكاليف الثابتة \\
\hline$\cdot, r V$ & 17,0 & & & الإيجار(1) \\
\hline$\cdot, \varepsilon$ & 1,10 & & & إهلاك المعدات و الألات \\
\hline$\cdot, 1$ & $\varepsilon, Y_{0}$ & & & الصيانة \\
\hline$\cdot, \cdot \mathrm{V}$ & $r, 0$ & & & الفائدة المقدرة علي ر أس المال \\
\hline$\cdot, 01$ & ro,o & & & إجمالي التكاليف الثَابتة \\
\hline $1 \ldots$ & $\varepsilon \varepsilon \Gamma \leq, r_{0}$ & & & إجمالي التكاليف الكلية \\
\hline
\end{tabular}

(1) تكاليف المدخلات غير التجارية: العمالة و المياه و الكهرباء و الإيجار.

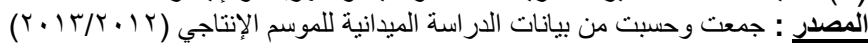

جدول رقم( • 1) هيكل التكاليف والإيراد الكلي لتصنيع طن لبن خام لمنتج الجبن الأبيض بمحافظة الفيوم عام

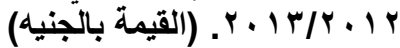

\begin{tabular}{|c|c|c|c|c|}
\hline الأهمية النسبية \% & القيمة للطن & 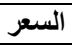 & الكمية للطن & 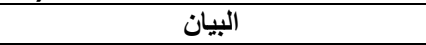 \\
\hline \multirow[t]{3}{*}{$1 \cdots$} & 7.1 & 19 & $r r$ & الكمية المنتجة من الجبن الأبيض كجم ( ) \\
\hline & $7 \cdot 1$. & & & الإيراد الكلي \\
\hline & & & & التكاليف المتغيرة \\
\hline $10, \leqslant V$ & $\varepsilon \varepsilon \cdots$ & $\varepsilon, \varepsilon$ & $1 \cdots$ & اللبن الخام \\
\hline $1, \leqslant 7$ & Vo & TO & $r$ & عدد العمالة (r) \\
\hline$\cdot, r$ & ir & & & المياه و الكهرباء (ץ) \\
\hline$V, V V$ & $\varepsilon \ldots$ & $1, r_{0}$ & r. & 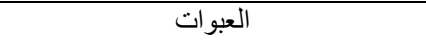 \\
\hline$r, \leqslant 9$ & 11. & & & الإضافات (r) \\
\hline$\cdot, \leqslant \wedge$ & ro & & & الوقود \\
\hline \multirow[t]{2}{*}{$9 \wedge, 9$} & 0.94 & & & إجمالي التكاليف المتغيرة \\
\hline & & & & التكاليف الثابتة \\
\hline$\cdot, 01$ & $r \uparrow, 0$ & & & الإيجار(Y) \\
\hline$\cdot, \cdot 9$ & 0 & & & إهلاك المعدات والألات \\
\hline$\cdot, \mu$ & 10,0 & & & الصيانة \\
\hline$\cdot, \mathrm{IV}$ & 9 & & & الفائدة المقدرة على رأس المال \\
\hline 1,1 & 07 & & & إجمالي التكاليف الثابتة \\
\hline $1 \cdots$ & $01 \leqslant 1$ & & & إجمالي التكاليف الكلية \\
\hline
\end{tabular}

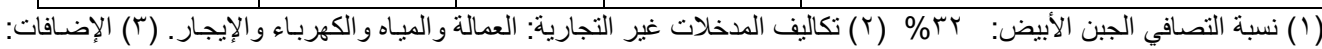

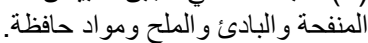

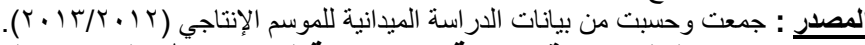

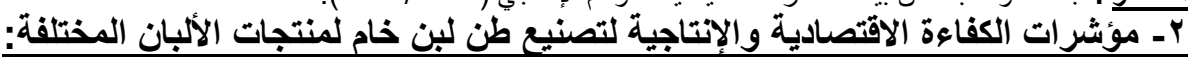

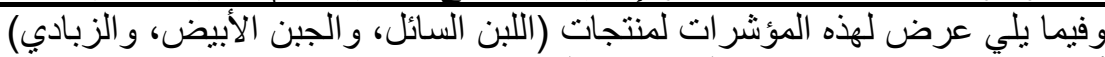

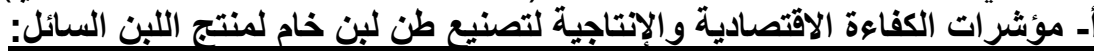

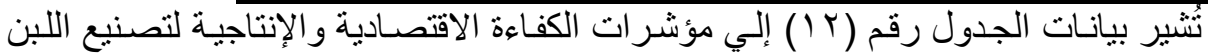

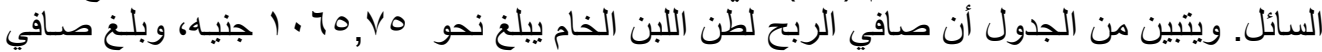

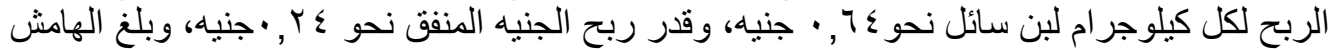

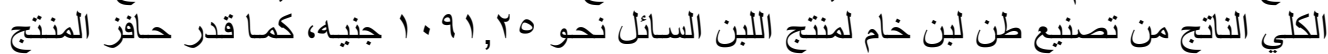
لكل كيلوجر ام لبن سائل نحو

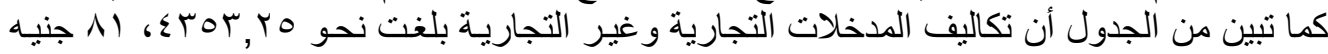

Fayoum J. Agric. Res. \& Dev., Vol. 30, No.1, January, 2016 
علي التو الي، وقدرت القيمة المضافة الناتجة من تصنيع طن لبن خام إلي لبن سـائل بنحو 11 ,

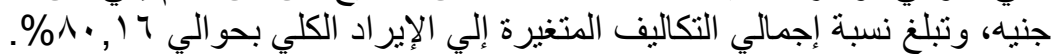

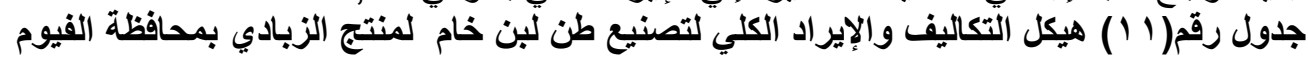

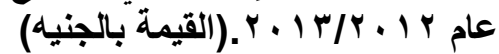

\begin{tabular}{|c|c|c|c|c|}
\hline الأهمية النسبية \% & القيمة بالجنيه للطن & | السعر بالجنيه للوحدة| & الكمية للطن & 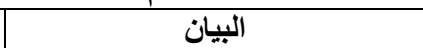 \\
\hline$\Lambda V, r V$ & $V r \ldots$ &,$\wedge$ & $9 \ldots$ & لكمية المنتجة من الزبادى (كوب) (1) \\
\hline Ir,Vr & 1.0. & ro & $\varepsilon Y$ & الكمية المنتجة من القتدةة \\
\hline \multirow[t]{2}{*}{$1 \ldots$} & AYO. & & & الإيراد الكلي \\
\hline & & & & التكاليف المتغيرة \\
\hline$V 7,7 r$ & $\varepsilon \varepsilon \ldots$ & $\varepsilon, \varepsilon$ & $1 \ldots$ & اللبن الخام \\
\hline $1, v \leq$ & $1 \ldots$ & ro & $\varepsilon$ & عدد العمالة (Y) \\
\hline$\cdot, Y Y$ & $1 \%, 0$ & & & المياه و الكهرباء (Y) \\
\hline $1 \wedge, \wedge$ & $1 \cdot \Lambda$. & $\cdot, 1 Y$ & $9 \ldots$ & عبو ات الزبادي (كوب) \\
\hline$\cdot, \wedge$ & $\varepsilon q, Y$ & $r, r$ & YI & عبو ات القشدة (عبوة) \\
\hline$\cdot, \varepsilon$ & $r \theta, 0$ & & & الإضـافات (r) \\
\hline$\cdot r$ & 19 & & & 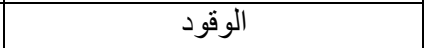 \\
\hline \multirow[t]{2}{*}{$q \wedge, q \vee$} & จ૫^r,r & & & إجمالي التكاليف المتغيرة \\
\hline & & & & التكاليف الثابتة \\
\hline$\cdot, 0$ & rq & & & الإيجار(r) \\
\hline$\cdot, 10$ & $\Lambda$ & & & إهلاك المعدات و الألات \\
\hline$\cdot, 17$ & 9,0 & & & الصيانة \\
\hline$\cdot, Y Y$ & $1 Y, 0$ & & & الفائدة المقدرة علي رأس المال \\
\hline $1, \cdot r$ & 09 & & & إجمالي التكاليف الثابتة \\
\hline $1 \ldots$ & $\Delta V \leqslant Y, r$ & & & إجمالي التكاليف الكلية \\
\hline
\end{tabular}

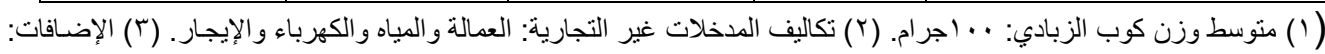

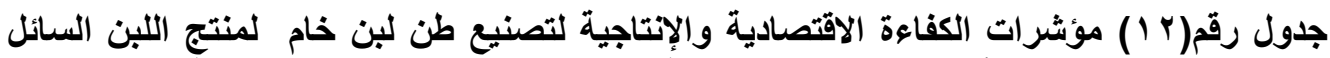

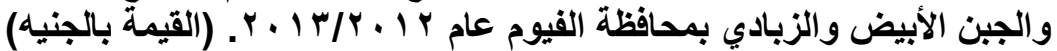

\begin{tabular}{|c|c|c|c|}
\hline \multicolumn{3}{|c|}{ القيمة } & \multirow[t]{2}{*}{ البيان } \\
\hline الزبادي & الجبن الأبيض & اللبن السائل & \\
\hline Aro. & $7 \cdot \Lambda$. & $00 \ldots$ & الإير اد الكلى \\
\hline $1, \cdot r$ & 1,1 & $\cdot, 01$ & التكاليف الإنتاجية الثابتة \% \\
\hline $91,9 \vee$ & 91,9 & $99, \leqslant Y$ & التكاليف الإنتاجية المتغيرة \% \\
\hline$O V \leqslant Y, Y$ & $01 \leqslant \wedge$ & $\varepsilon \leqslant \Gamma \leqslant, r_{0}$ & إجمالي تكاليف التصنيع \\
\hline $07 \cdots, V$ & $0 . r \leqslant, 0$ & ETOr, ro & تكاليف المدخلات التجارية \\
\hline $1 \leq 1,0$ & $11 r, 0$ & $\wedge 1$ & تكاليف المدخلات غبر التجارية \\
\hline$r 0 \cdot v, \Lambda$ & $9 \pi r$ & $1.70,10$ & الربح لطن اللبن \\
\hline$\cdot, Y \leq$ & $1, r_{0}$ & $\cdot, 7 \varepsilon$ & الربح لكل كيلوجر ام اللبن \\
\hline$\cdot, \leqslant \Gamma$ & $\cdot, 11$ & $\cdot, Y \varepsilon$ & الربح للجنيه المنفق \\
\hline
\end{tabular}

Fayoum J. Agric. Res. \& Dev., Vol. 30, No.1, January, 2016 
Vo

\begin{tabular}{|c|c|c|c|}
\hline roTt,A & $9 \wedge \wedge$ & $1.91,10$ & الهامش الكلي \\
\hline$r \varepsilon, \wedge r$ & $\varepsilon, q$ & 10,0 & حافز المصنع لكل كيلوجر ام اللبن \% \\
\hline$\cdot, r \leq$ & $1, r_{0}$ & $\cdot, 7 \varepsilon$ & هامش المصنع لكل كيلوجر ام اللبن \\
\hline$r \neg \leqslant q, r$ & $1 \cdot \leqslant 0,0$ & $11 \leqslant 7,10$ & القيمة المضافة للمصنع \\
\hline$\uparrow \wedge, \wedge \Lambda$ & AT,Vo & $\Lambda \cdot, 17$ & إجمالي التكاليف المتغيرة/ الإير اد الكلي \% \\
\hline
\end{tabular}

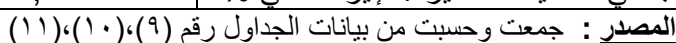

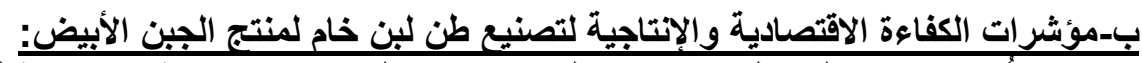

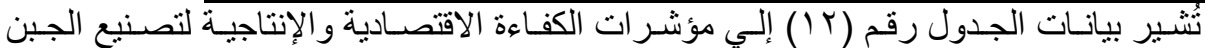

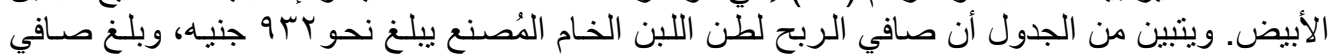

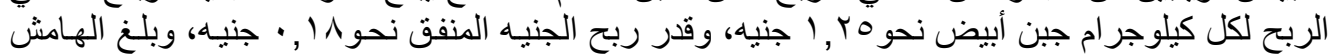

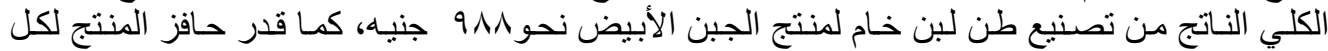

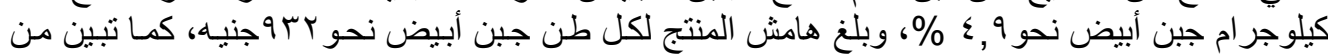

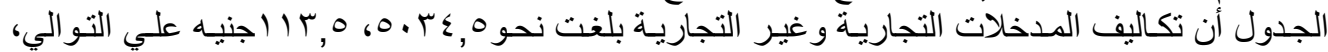

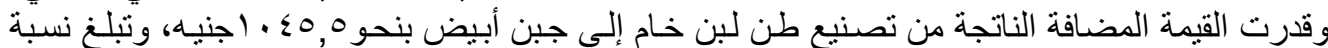

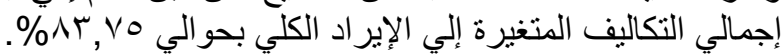

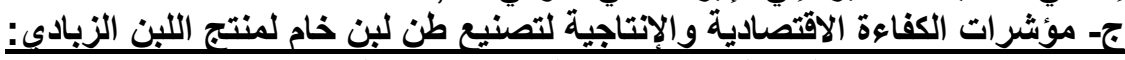

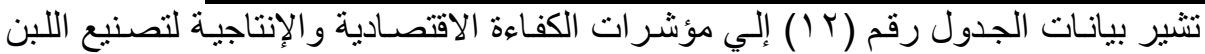

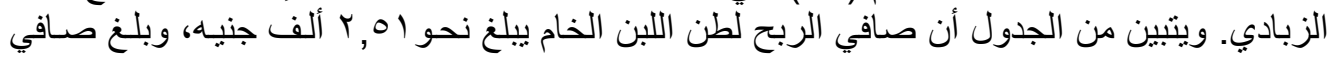

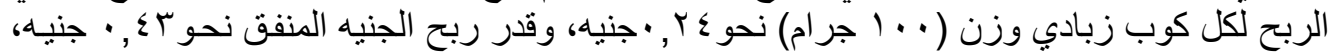

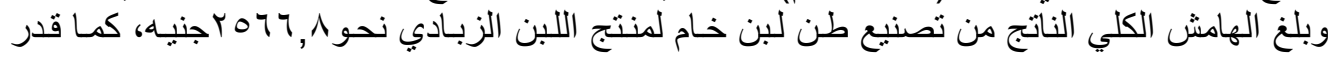

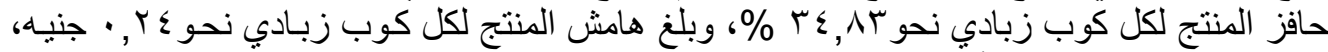

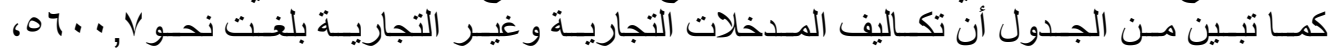

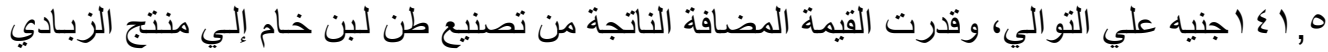

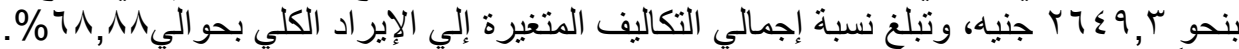

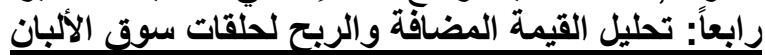

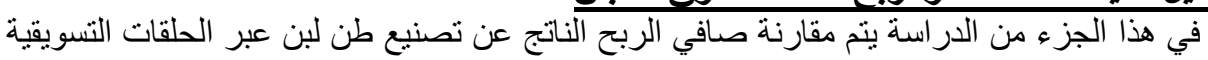

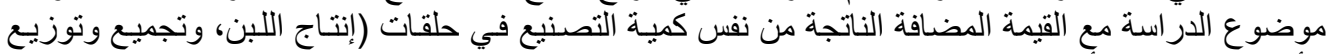

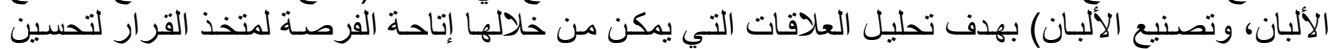
تافسية بعض الحلقات في مقابل الحلقات الأخري.

الربح والقيمة المضافة الناتجة من إنتاج وتصنيع طن لبن عبر حلقات السوق :

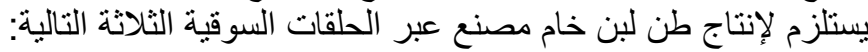

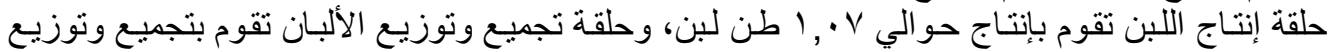

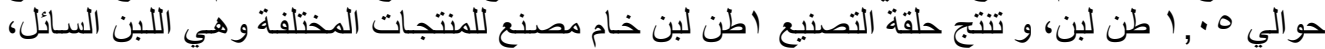

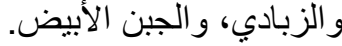

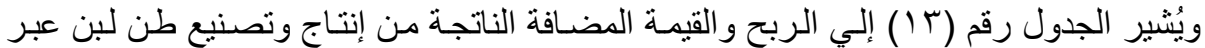

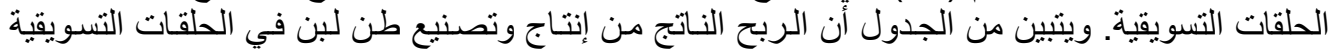

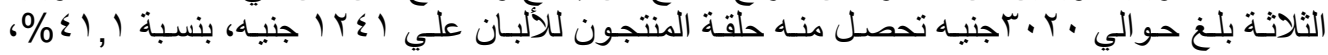

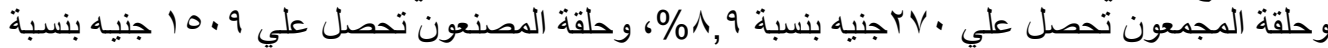

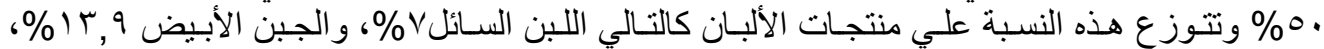

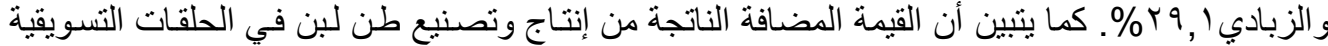

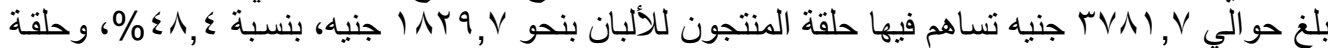

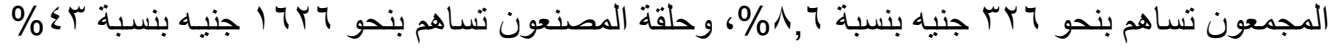

Fayoum J. Agric. Res. \& Dev., Vol. 30, No.1, January, 2016 
V

وتتوزع هذه النسبة علي منتجات الألبان كالتالي اللبن السائلج\%، و الجبن الأبيض 0, r \%؛، والزبادي $\% r \leqslant, 0$

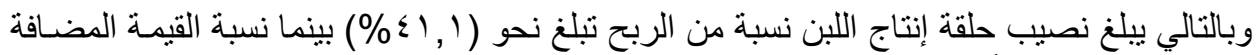

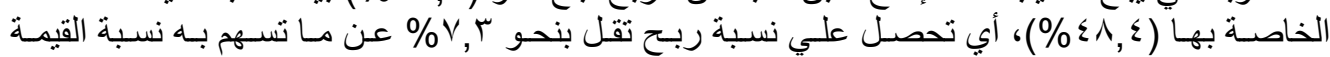

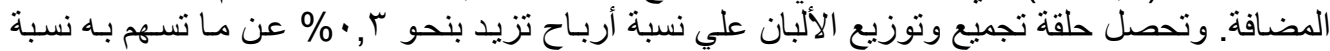

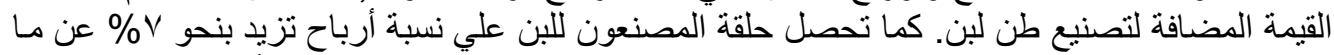

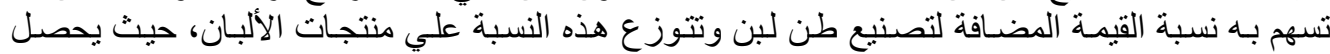

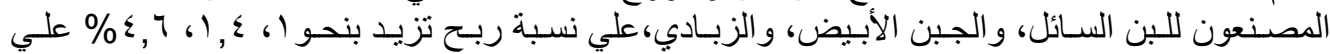

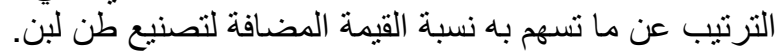

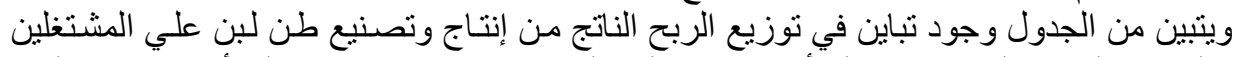

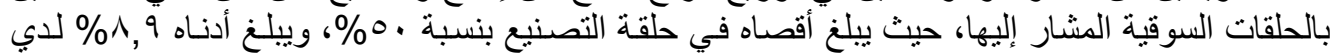

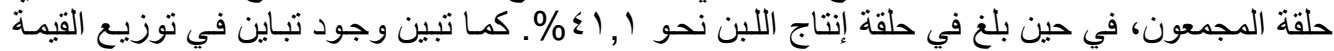

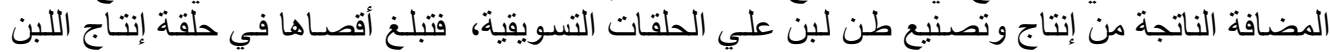

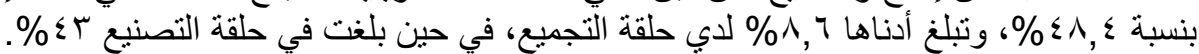

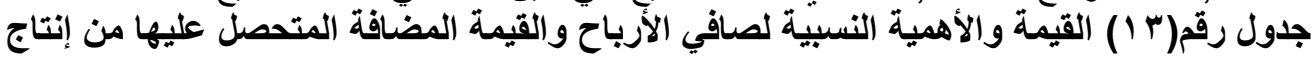

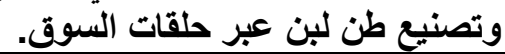

\begin{tabular}{|c|c|c|c|c|c|c|c|}
\hline $\begin{array}{l}\text { الأهبية } \\
\text { \% }\end{array}$ & القالجناتجة المضافة & الألهبية & الزبنج & القيمة المضن & بالجنيه & المستخدمة & حلقات السوق \\
\hline$\varepsilon \Lambda, \varepsilon$ & $1 \wedge r q, Y$ & $\varepsilon 1,1$ & $\mid r \varepsilon 1$ & $\mid V I$. & 117. & $1, \cdot v$ & حلقة إنتاج اللبن \\
\hline$\Lambda, 7$ & rYT & $\Lambda, 9$ & TV. & $\Gamma \cdot \cdot, \tau$ & TOV & $1, .0$ & حلقة تجميع الألبان \\
\hline$\varepsilon r$ & 1747 & 0. & 10.9 & & & 1 & حلقة تصنيع الألبان \\
\hline 7 & rrq & v & TIT & $11 \leq 7$ & 1.70 & $\cdot, r$ & 1 - اللبن السائل \\
\hline $1 r, 0$ & $\varepsilon v$. & $1 \pi, 9$ & $\$ 19$ & $1 . \leqslant 0$ & QTY & $\cdot, \leqslant 0$ & r- الجبن الأبيض \\
\hline$r \leqslant, 0$ & GYV & $r q, 1$ & AVV & $r \quad \leqslant 9$ & ro.r & $\cdot$, ro & r- الزبادي \\
\hline $1 \ldots$ & rVAI,Y & $1 \ldots$ & T.r. & & & & الإجمالي \\
\hline
\end{tabular}

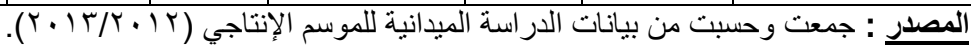

الملخص وتوصيات

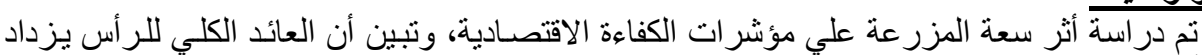

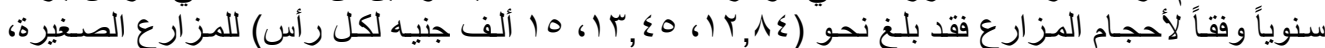

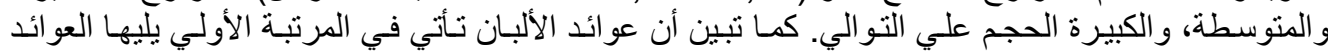

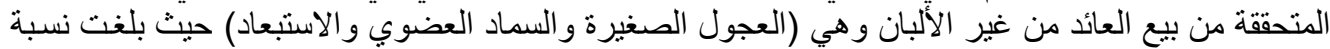

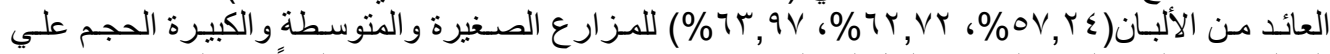

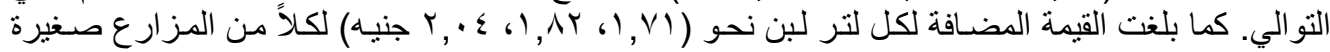

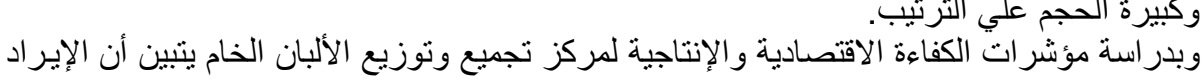

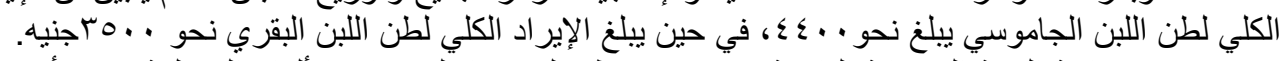

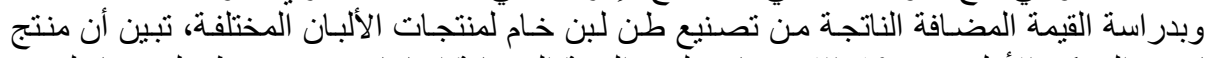

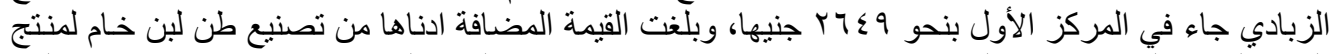

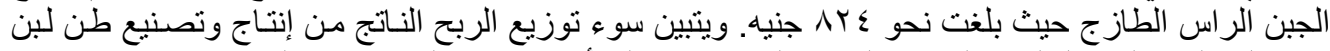

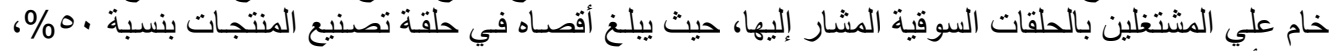

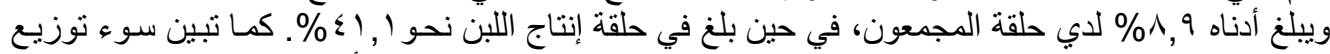

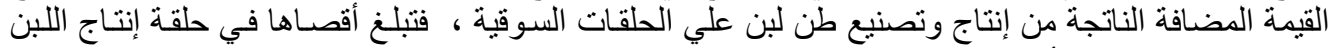

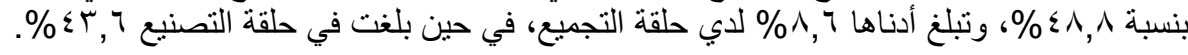

Fayoum J. Agric. Res. \& Dev., Vol. 30, No.1, January, 2016 


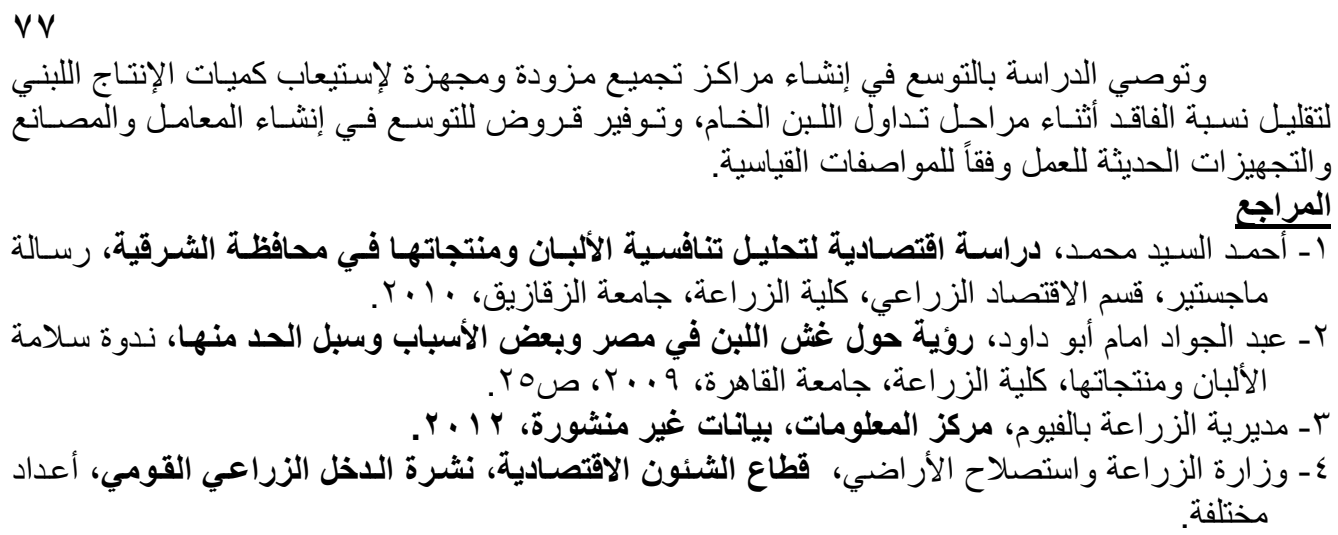

\title{
THE ECONOMIC EFFICIENCY OF THE PROCESSING CHAINS OF DAIRY PRODUCTS IN FAYOUM GOVERNORATE
}

Department of Agricultural Economics, Faculty of Agriculture,

Fayoum University, Fayoum

\begin{abstract}
By studying the impact of farm size on the economic efficiency indicators; it can be realized that the annual return on a head of a herd increases annually for small, medium, and large scale farms by 12840, 13450, and 15000 EGP respectively. The relative importance of different sources of income can be ranked as follows; selling dairy products and selling non-dairy products. The returns on dairy products have been estimated at $57.24 \%, 62.72 \%$, and $63.97 \%$ for small, medium, and large scale farms respectively. It can be mentioned also that the return on milk is positively impacted by farm sizes where the value added per liter is $1.71,1.82$, and 2.04 for small, medium, and large scale farms. The ratio of operating costs to the total revenue is negatively impacted by farm sizes where the ratio is estimated at 77.2, 72.6, and 54.9 for small, medium, and large scale farms. As an overall conclusion it can be said that the large farms would achieve better economic efficiency indicators.
\end{abstract}

Fayoum J. Agric. Res. \& Dev., Vol. 30, No.1, January, 2016 